\title{
Enseñanza de la construcción tradicional y resiliencia climática
}

\author{
Pedro P. Palazzo \\ 6 de julio de 202I
}

Se proclama a menudo que el desarrollo sostenible, la conservación del patrimonio y la práctica corriente de la construcción son aspectos de una misma disciplina integrada de la arquitectura. La misma existencia de cierto edificio histórico implica ahorro energético y captura de carbono mucho más grandes que la más eficiente nueva construcción. Sin embargo, las capacidades técnicas para dar mantenimiento a las estructuras tradicionales, suelen ser muy distintas de la tecnología industrial asociada al desarrollo sostenible. Asimismo es peor cuando se habla del infame « retrofit energético », el que hace parecer que los edificios históricos sean inferiores a la nueva construcción desde el punto de vista ambiental. Estas diferencias no son disparidades superficiales entre objetivos convergentes, sino que muestran una incompatibilidad de principios entre determinada cultura de patrimonio a la que interesa lo existente, lo regional y lo artesanal, y la cultura del desarrollo industrial dedicada a producir y desechar siempre más, aunque produzca y deseche productos con la etiqueta « ecológica $\gg$.

Es cierto que, para solucionar esta disparidad, habrá que actuar sobre las estructuras productivas del mercado inmobiliario, pero para que cambien las estructuras hay que existir aptitud técnica alternativa en la construcción y en su regulación. Por eso, la formación de arquitectos tiene un papel central en ese proceso. El ideal universitario de un arquitecto apto a comprender los retos de la construcción corriente, de la resiliencia climática y del patrimonio cultural es ampliamente reconocido, pero no se lo podrá alcanzar en la práctica mientras enseñemos a nuestros estudiantes que los principios de conservación de sitios históricos pertenecen a un nicho totalmente distinto de las tecnologías y normas de la eficiencia energética, cuando en verdad la conservación del patrimonio es la herramienta más eficaz para alcanzar una reducción global del consumo energético.

La clave para alcanzar esta integración está en ubicar la enseñanza de los métodos tradicionales de construcción con materiales regionales en el centro de los programas de estudios en arquitectura. La aptitud para emplear de modo corriente estos materiales de baja energía incorporada y para hacerlo en armonía con el carácter de las construcciones vernáculas será capaz de cerrar la brecha conceptual entre la conservación de edificios de valor patrimonial y las metas de reducción de emisiones de carbono en la industria de la construcción. El principal obstáculo a esta propuesta es que sería mucho más caro construir de ese modo, que hacerlo con materiales industrializados: cuesta más trabajo humano cómo para compensar el menor consumo de energía industrial, y desde luego cuesta más 
dinero y más tiempo. Así que, ¿es realista, o incluso moral, exigir una adhesión sistemática a métodos menos eficientes, afuera el dominio de la conservación del patrimonio?

A eso opongo que el bajo costo de la construcción industrializada es lo que ha permitido que ella se convirtiera en una inversión especulativa a corto plazo, resultando en la rápida destrucción del patrimonio histórico y multiplicando más aún el daño climático de sus procesos productivos. En cambio, una cultura constructiva más costosa beneficia el mantenimiento de edificios existentes. Una preferencia técnica y normativa por el uso de materiales y técnicas tradicionales es, en resumen, una subvención en favor del desarrollo sostenible y una tasa sobre las externalidades ecológicas negativas de la construcción industrializada.

Además de los resultados ambientales que advienen de las propiedades intrínsecas de los materiales, la construcción tradicional favorece un proceso productivo sostenible en otros aspectos. Una de las más críticas consecuencias del cambio climático es el desplazamiento de procesos productivos que se organizan en cadenas globales y la consecuente privación económica de comunidades locales. La construcción tradicional no solo contribuye a la lucha directa contra el cambio climático, como también refuerza cadenas productivas en escala local y regional. En este proceso también están involucrados los arquitectos: hoy día, muchas universidades están en competencia para demostrar que son más « globales » que otras; pero, una vez que todas las escuelas de arquitectura se hayan convertido en escuelas « globales », ¿qué más bien va a distinguir una facultad en el País Vasco de otra en Andalucía, y ambas de una escuela en Brasil o China? La enseñanza de las características regionales ha sido relegada a unas fórmulas abstractas de confort térmico o luminoso, así que a la especialización en patrimonio.

De hecho, un joven arquitecto local no está mejor ubicado para proyectar en su propia ciudad que una « estrella » internacional experimentada, ni posee aptitud para preferir los materiales de su región, producidos por pequeñas empresas locales, a lo que vea en los catálogos de productos industrializados y quizás importados. A eso se añade que el empleo de materiales y procesos naturales suele ser dificultado por bienintencionados requisitos de rendimiento certificado, que solo los productos industrializados pueden cumplir. Con todo eso, las capacidades técnicas, los empleos calificados y lo que cobran son desviados de muchas de nuestras regiones para concentrarse cada vez más en unos pocos centros industriales globales. Desde luego, la crisis provocada por la construcción industrializada no es solo climática y cultural, sino que sobretodo económica y social. Para capturar localmente las ganancias que puede generar la construcción tradicional, se necesita, por lo tanto, que las escuelas de arquitectura se vuelvan locales, así como los demás eslabones de la cadena productiva del edificado.

En suma, la enseñanza de arquitectura reproduce las derivas conceptuales y técnicas que alejan la conservación del patrimonio de las políticas de lucha contra el cambio climático. Para que esta integración ocurra verdaderamente, se necesita plantear el conocimiento operativo de la construcción tradicional no como especialidad del patrimonio, sino que como aptitud corriente en la formación de arquitectos. El empleo de materiales y procesos tradicionales aún necesita superar el marco normativo en vigor, que privilegia los productos industrializados con rendimiento certificado, y eso también depende de una tomada de conciencia por parte de arquitectos y de escuelas. A ejemplo del movimiento slow food, que involucra productos y productores regionales, la lucha contra el cambio climático implica educar a los arquitectos para que valoren la cultura del slow building. 